Part 2

Passivation and

Surface Treatment 



\section{Reinforcement of CuZn coatings obtained by electrodeposition from a free-of-cyanide alkaline solution containing $\mathrm{Al}_{2} \mathrm{O}_{3}$ hard particles}
A. P. R. de Almeida'
I. A. Carlos $^{3}$
F. D. D. dos Santos'
P. C. Tulio'
Z. A. Mahnud²

\section{Abstract}

An alkaline free-of-cyanide electrodeposition solution using sorbitol as complexing agent was employed for obtaining metal-matrix-composite coatings of $\mathrm{CuZn}-\mathrm{Al}_{2} \mathrm{O}_{3}$. These coatings consisted of $\mathrm{CuZn}$ as metal matrix and hard micrometric alumina $\left(\mathrm{Al}_{2} \mathrm{O}_{3}\right)$ particles as the dispersed phase. These composite coatings could be employed in protection of metallic pieces subjected to erosion-corrosion, since they will combine corrosion resistance of the $\mathrm{CuZn}$ matrix and mechanical resistance given by the hard $\mathrm{Al}_{2} \mathrm{O}_{3}$ particles. It is shown that these coatings could be obtained from the proposed solution, but only in high electrodeposition cathodic current densities $\left(\mathrm{i}_{\mathrm{g}}\right)$, for $1 / 2 \mathrm{i}_{\mathrm{g}}{ }_{1}^{1 / 2}>15 \mathrm{mAcm}^{-2}$. Vickers microhardness $(\mathrm{MH})$ of the composite coatings was significantly increased when comparing with pure $\mathrm{CuZn}$ coatings for $\mathrm{i}_{\mathrm{g}}$ of -25 and $-30 \mathrm{mAcm}^{-2}$. The increased microhardness is due to occluded $\mathrm{Al}_{2} \mathrm{O}_{3}$, since it was not observed grain refinement due to $\mathrm{Al}_{2} \mathrm{O}_{3}$. Based on these results, $\mathrm{CuZn}-\mathrm{Al}_{2} \mathrm{O}_{3}$ composite coatings have prospects for erosion-corrosion protection.

Keywords: electrodeposition; $\mathrm{CuZn}-\mathrm{Al}_{2} \mathrm{O}_{3}$ composite; sorbitol alkaline solution

1 Federal University of Technology - Cornélio Procópio - Paraná - Brasil.

2 Instituto Nacional de Tecnología Industrial - INTI, Buenos Aires - Argentina.

3 Chemistry Department, Federal University of São Carlos - São Carlos - São Paulo - Brasil. 


\section{Introduction}

Corrosion or some form of environmentally assisted cracking of metals have safety and economic impacts. It is well known that about 3.5\% of Gross National Product of countries is related to direct costs with corrosion (Verinck, 2000, p. 1; Davis, 2000, p. 10; Schweitzer, 2010, p.1). The search for methods to minimize and control the corrosion is, then, an active area of research and development.

Erosion-corrosion is a form of degradation of metal properties which involves synergism between the corrosion (anodic dissolution of the metal) and a mechanical action (erosion). This joined action accelerates degradation of metal properties (Davis, 2000, p. 134; Schweitzer, 2010, p. 44; Postlethwaite, 2010, p. 250). Erosion can be caused by, for example, impingement of solid particles in a liquid fluid, impingement of liquid droplets in high-speed gas or vapor flows and cavitation. This impingement can destroy protective passive layers or induce deformations in the surface which can increase the corrosion rate of the metal (Postlethwaite, 2010, p. 250; Fontana, 1967, p. 82). High corrosion resistance stainless steel could be employed to minimize corrosion but it is an expensive method (Postlethwaite, 2010, p. 250). On the other hand, hard materials could be employed to eliminate the erosion problem but they are hard to weld and often brittle (Postlethwaite, 2010, p. 250).

Metal-matrix-composites could be employed to increase erosion-corrosion resistance, since they combine high corrosion resistance of metal-matrixes and mechanical resistance given by hard particles of the dispersed phase (Kainer, 2006, p. 1). Metalmatrix-composites can be obtained as coatings by the electrodeposition technique (Walsh, 2015; Hovestad, 1995; Musiani, 2010; Tulio, 2007). An example of corrosion resistant metal-matrix is $\mathrm{CuZn}$ alloys. If in the $\mathrm{CuZn}$ matrix abrasive hard particles of alumina $\left(\mathrm{Al}_{2} \mathrm{O}_{3}\right)$ were dispersed, the hardness of the composite could be increased. CuZn (brass) can be commercially obtained by electrodeposition, but from cyanide containing solutions, since the ion cyanide is an excellent complexing agent, furnishing commercially accepted electrodeposited films (Geisman, 1974, p. 506; Parthasaradhy, 2009, p. 212; Vagramyan, 1979). Cyanide, however, has environmental and health concerns (Dash, 2009). Extensive research for less aggressive complexing agents is in course (Johannsen, 2001; Ballesteros, 2014; Survila, 2013). One example is sorbitol (de Almeida, 2015), in which the baths can give CuZn films fine-grained, uniform, smooth and with distinct colorations.

The first aim of the present work was to obtain metal-matrix-composite coatings of $\mathrm{CuZn}-\mathrm{Al}_{2} \mathrm{O}_{3}$ from a sorbitol alkaline non-cyanide electrodeposition solution. After this obtainment, erosion resistance of the coatings was evaluated by microhardness measurements. 


\section{Experimental}

The electrodeposition solution consisted of: $\mathrm{CuSO}_{4} \cdot 5 \mathrm{H}_{2} \mathrm{O} 0.14 \mathrm{M}+\mathrm{Zn}$ $\mathrm{SO}_{4} .7 \mathrm{H}_{2} \mathrm{O} 0.06 \mathrm{M}+\mathrm{NaOH} 3 \mathrm{M}+\mathrm{D}(-)$ Sorbitol $\left(\mathrm{C}_{6} \mathrm{H}_{14} \mathrm{O}_{6}\right) 0.2 \mathrm{M}$. This alkaline solution has sorbitol as the complexing agent. It was developed by de Almeida et al. (de Almeida, 2015). For obtaining composite coatings, micrometric alumina particles $\left(\mathrm{Al}_{2} \mathrm{O}_{3}\right), 99.85 \%$, mean diameter of $3.4 \mu \mathrm{m}$ ) particles (Treibacher-Schleifmittel Brazil Ltd.) were added, asreceived, to the electrodeposition solution. Particles were added up to a mass of $\mathrm{Al}_{2} \mathrm{O}_{3}$ to volume of solution ratios $\left(\mathrm{C}_{\mathrm{Al2O} 3}\right)$ of 10 and $20 \mathrm{gL}^{-1}$. Before the electrodeposition, the solution containing $\mathrm{Al}_{2} \mathrm{O}_{3}$ particles was mechanically stirred for $12 \mathrm{~h}$. The substrate consisted of rectangular 1020 steel plates, embedded in epoxy resin, with only one face exposed to the solution, with an electroactive area of $4.8 \mathrm{~cm}^{2}$. The substrates (electrodes) were sanded up to 600 emery papers, washed in distilled water, immersed in acetone and dried before electrodeposition. The anode was a large rod of electrolytic copper placed in front of the substrate. Electrodeposition was performed under constant cathodic current densities $\left(\mathrm{i}_{\mathrm{g}}\right)$ for a time of deposition which corresponded to a charge density $\left(\mathrm{q}_{\mathrm{dep}}\right)$ of $72.5 \mathrm{Ccm}^{-2}$. This charge density corresponds to a theoretical coating thickness of $30 \mu \mathrm{m}$. During electrodeposition, magnetic stirring of the solution was maintained.

Scanning electron microscopy (SEM) and semiquantitative energy-dispesive X-ray spectroscopy (EDS) chemical analysis were performed with a FEI Quanta 200 microscope coupled with an EDS-Oxford INCA. For EDS, a large central area of $2.4 \times 2.1 \mathrm{~mm}^{2}$ was analyzed.

The Vickers microhardness of the electrodeposited coatings was performed on three distinct samples of the same coating and it was a result of a minimum of 10 measures in a large central area of each sample coating. Microhardness measurements were performed by a microhardness tester model HV-1000B.

\section{Results and discussion}

\subsection{Electrodeposition of $\mathrm{CuZn}-\mathrm{Al}_{2} \mathrm{O}_{3}$}

Electrodeposition was performed, initially, at $\mathrm{i}_{\mathrm{g}}$ of -10 and $-20 \mathrm{mAcm}^{-2}$ and for $\mathrm{C}_{\mathrm{Al2O} 3}$ of 10 and $20 \mathrm{gL}^{-1}$. It was verified that the best conditions for $\mathrm{Al}_{2} \mathrm{O}_{3}$ occlusion in the $\mathrm{CuZn}$ metal matrix were at high $\mathrm{i}_{\mathrm{g}}\left(-20 \mathrm{mAcm}^{-2}\right)$ and $\mathrm{C}_{\mathrm{Al} 2 \mathrm{O} 3}$ of $20 \mathrm{gL}^{-1}$. This was verified by means of SEM analysis. In Figures 1 and 2 some SEM micrographies are shown for $\mathrm{i}_{\mathrm{g}}$ of $-20 \mathrm{mAcm}^{-2}$ and $\mathrm{C}_{\mathrm{Al} 2 \mathrm{O} 3}$ of $0 \mathrm{gL}^{-1}$ (Figure 1 ) and $\mathrm{C}_{\mathrm{Al} 2 \mathrm{O} 3}$ of $20 \mathrm{gL}^{-1}$ (Figure 2). In Figure 2 some partially occluded $\mathrm{Al}_{2} \mathrm{O}_{3}$ particles can be seen, meaning 
that there must be occluded particles in the matrix. EDS analysis confirmed the presence of the particles and it was possible to obtain $\mathrm{CuZn}-\mathrm{Al}_{2} \mathrm{O}_{3}$ metal-matrix composites form this sorbitol alkaline solution. Under conditions of $\mathrm{i}_{\mathrm{g}}$ of $-10 \mathrm{mAcm}$ ${ }^{2}$ and $10 \mathrm{gL}^{-1}$ it was difficult to visualize $\mathrm{Al}_{2} \mathrm{O}_{3}$ particles and the surface morphology is very close to the $\mathrm{CuZn}$ matrix obtained from $\mathrm{C}_{\mathrm{Al2}}$ of of $0 \mathrm{gL}^{-1}$. That means, practically no occlusion of $\mathrm{Al}_{2} \mathrm{O}_{3}$. These observations, as will be seen ahead, will reflect in very similar microhardness values for lowest $\mathrm{i}_{\mathrm{g}}$ at $\mathrm{C}_{\mathrm{Al} 2 \mathrm{O} 3}$ of 0,10 and $20 \mathrm{gL}^{-1}$.

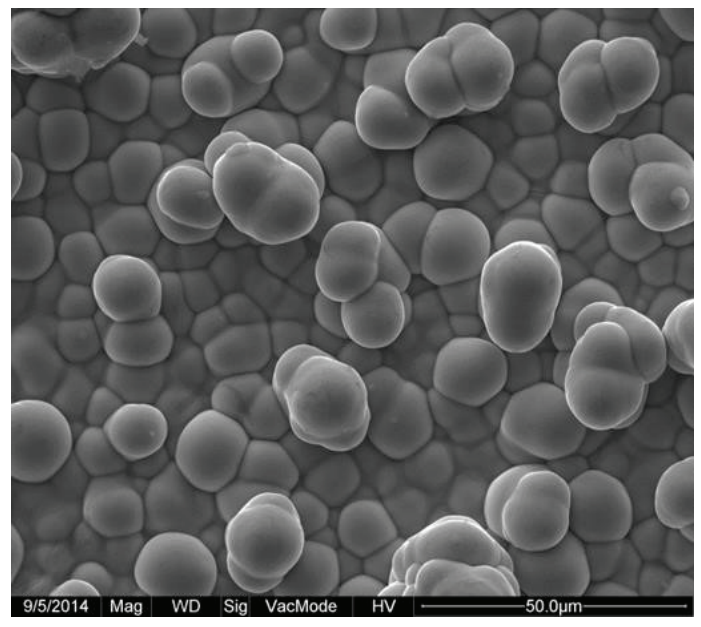

Figure 1 SEM micrography of a typical CuZn coating obtained in the electrodeposition solution without $\mathrm{Al}_{2} \mathrm{O}_{3}$ particles $\left(\mathrm{C}_{\mathrm{AL203}}=0 \mathrm{gL}^{-1}\right) . \mathrm{i}_{\mathrm{g}}=-20 \mathrm{mAcm}^{-2}$.

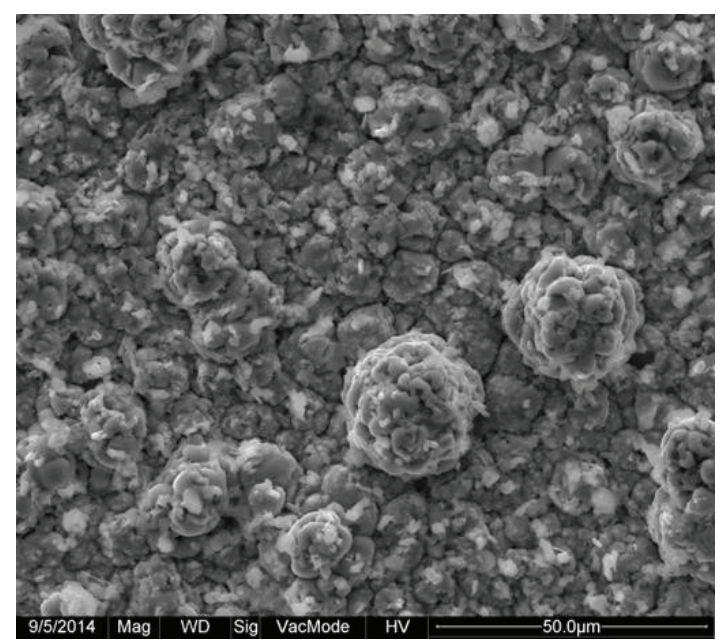

Figure 2 SEM micrography of a typical CuZn-Al $\mathrm{O}_{3}$ coating obtained in the electrodeposition solution with $\mathrm{C}_{\mathrm{AL203}}=10$ $\mathrm{gL}^{-1} \cdot \mathrm{i}_{\mathrm{g}}=-20 \mathrm{mAcm}^{-2}$. 


\subsection{Microhardness of the coatings}

In Figure 3 are shown the microhardness $(\mathrm{MH})$ results for coatings obtained in these two first $\mathrm{i}_{\mathrm{g}}$ and $\mathrm{C}_{\mathrm{Al} 2 \mathrm{O} 3}$ of 0,10 and $20 \mathrm{gL}^{-1}$. By analyzing the mean values it is clear the tendency of increase in $\mathrm{MH}$ for higher $\mathrm{i}_{\mathrm{g}}$ and $\mathrm{C}_{\mathrm{Al} 2 \mathrm{O} 3}$. These results are in agreement with the SEM analysis above, where occlusion of $\mathrm{Al}_{2} \mathrm{O}_{3}$ was predominant for high $\mathrm{i}_{\mathrm{g}}$ and $\mathrm{C}_{\mathrm{Al} 2 \mathrm{O} 3}$. For $-10 \mathrm{mAcm}^{-2}$ it has practically no change in $\mathrm{MH}$, since there is not occlusion of $\mathrm{Al}_{2} \mathrm{O}_{3}$ as evidenced by SEM. The increase in $\mathrm{MH}$ can be only attributed to the $\mathrm{Al}_{2} \mathrm{O}_{3}$ particles, since no grain refinement is observed for the $\mathrm{CuZn}-\mathrm{Al}_{2} \mathrm{O}_{3}$ when compared with $\mathrm{CuZn}$ (obtained from $\mathrm{C}_{\mathrm{Al} 203}$ of $0 \mathrm{gL}^{-1}$ ), as could be visualized in Figures 1 and 2 .

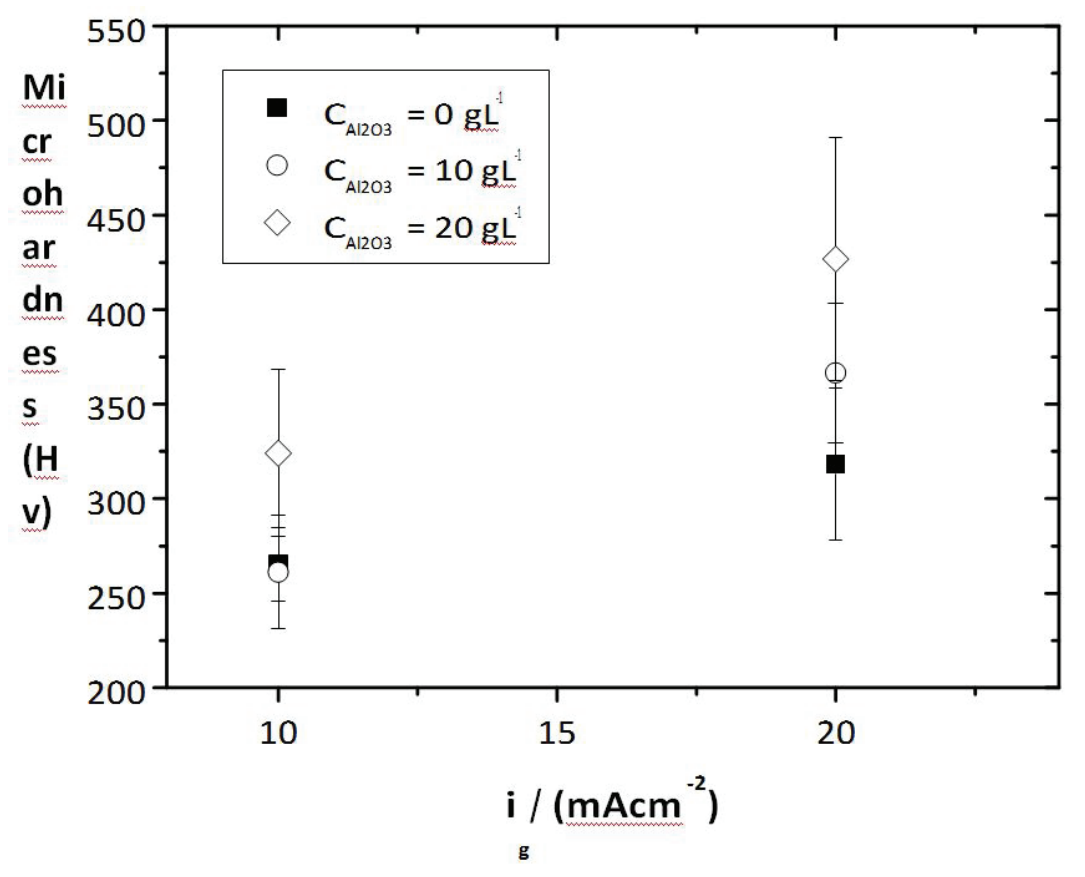

Figure 3 Vickers microhardness of CuZn coatings as a function of $i_{g}$ and $C_{\text {AL203 }}$.

Based on the results of Figure 3, an extended range of $i_{g}$ was analyzed, focusing higher $\mathrm{i}_{\mathrm{g}}$ and for $\mathrm{C}_{\mathrm{Al2O}}$ of $10 \mathrm{gL}^{-1}$. In Figure 4 are shown the results for $\mathrm{MH}$.

It is clearly observed in Figure 4 that the choice for higher $\mathrm{i}_{\mathrm{g}}$ was confirmed for obtainment of high microhardness $\mathrm{CuZn}-\mathrm{Al}_{2} \mathrm{O}_{3}$ composite coatings. For $\mathrm{i}_{\mathrm{g}}$ of -10 and $15 \mathrm{mAcm}^{-2}$ there is no change in $\mathrm{MH}$, showing that occlusion of $\mathrm{Al}_{2} \mathrm{O}_{3}$ is difficult at these low $\mathrm{i}_{\mathrm{g}}$. SEM micrographies of the high $\mathrm{i}_{\mathrm{g}}$ coatings have not shown clear grain refinement and the increase in $\mathrm{MH}$ is due to the $\mathrm{Al}_{2} \mathrm{O}_{3}$ particles 
present in the CuZn matrix. Occluded and partially occluded $\mathrm{Al}_{2} \mathrm{O}_{3}$ particles acts in hindering of dislocations, increasing $\mathrm{MH}$.

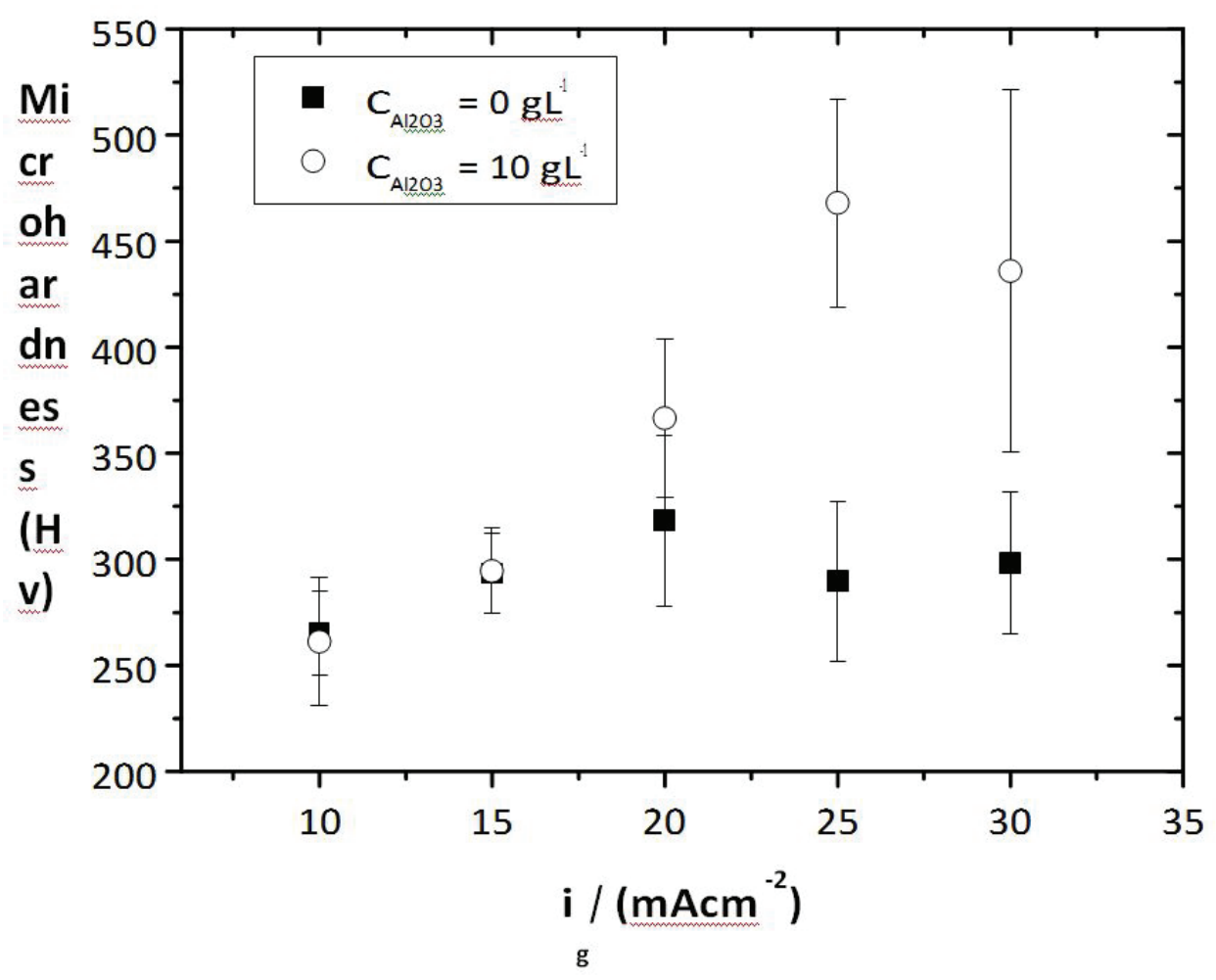

Figure 4 Vickers microhardness of CuZn coatings as a function of $\mathrm{i}_{\mathrm{g}}$ for $\mathrm{C}_{\mathrm{AL} 203}$ of $10 \mathrm{gL}^{-1}$.

As microhardness is related with the resistance to plastic deformation, these results for

$\mathrm{CuZn}-\mathrm{Al}_{2} \mathrm{O}_{3}$ coatings indicates that they could be employed as coatings against erosion, including cavitation. It must be pointed out that microhardness results alone are not necessarily a good criterion for erosion-corrosion resistance (Fontana, 1967, p. 82). Other experiments are necessary.

\section{Conclusion}

$\mathrm{CuZn}-\mathrm{Al}_{2} \mathrm{O}_{3}$ composite coatings could be obtained by electrodeposition from a free-ofcyanide solution containing sorbitol and in high alkaline $\mathrm{pH}$.

The best conditions for this obtainment were for higher electrodeposition current densities $\left(1 / 2 \mathrm{i}_{\mathrm{g}} \frac{1}{2}>15 \mathrm{mAcm}^{-2}\right)$. For low $\mathrm{i}_{\mathrm{g}}$, practically no occlusion of $\mathrm{Al}_{2} \mathrm{O}_{3}$ was observed. 
Microhardness of $\mathrm{CuZn}-\mathrm{Al}_{2} \mathrm{O}_{3}$ increased significantly for coatings obtained in $\mathrm{i}_{\mathrm{g}}$ of -25 and $-30 \mathrm{mAcm}^{-2}$ when compared to $\mathrm{CuZn}$.

Coatings of $\mathrm{CuZn}-\mathrm{Al}_{2} \mathrm{O}_{3}$ could have prospects for applications as erosion resistant coatings.

\section{References}

BALLESTEROS, J. C.; TORRES-MARTINEZ, L. M.; JUÁREZ-RAMIRES, I.; TREJO, G.; MEAS, Y. Study of the electrochemical co-reduction of $\mathrm{Cu}^{2+}$ and $\mathrm{Zn}^{2+}$ ions from an alkaline non-cyanide solution containing glycine. J. Electroanal. Chem. 727:104-112. 2014.

DASH, R. R.; GAUR, A.; BALOMAJUMDER, C. Cyanide in industrial wastewaters and its removal: a review on biotreatment. J. Hazard. Mater. 163:1-11. 2009.

DAVIS, H. R. Corrosion - understanding the basics. Materials Park-Ohio: ASM International, 2000.

DE ALMEIDA, M. R. H.; CARVALHO, M. F.; BARBANO, E. P.; TULIO, P. C.; CARLOS, I. A. Copper-zinc electrodeposition in alkaline-sorbitol medium: electrochemical studies and structural, morphological and chemical composition characterization. Appl. Surf. Sci. 333:13-22. 2015.

FONTANA, M. G.; GREENE, N. D. Corrosion engineering. New York: McGraw-Hill, 1967.

GEISMAN, W. C.; BENNETT, D. J. Brass. In: LOWENHEIM, F. A. (ed) Modern electroplating. New York: John Wiley \& Sons, 1974.

HOVESTAD, A.; JANSEEN, L. J. J. Electrochemical codeposition of inert particles in a metallic matrix. J. Appl. Electrochem. 25:519-527. 1995.

JOHANNSEN, K. Effect of temperature \& bulk stirring on electroplating of brass from pyrophosphate electrolyte. Plat. Surf. Finish. 88:104-108. 2001.

KAINER, K. U. Basics of metal matrix composites. In: KAINER, K. U. (ed) Metal matrix composites. Custom-made materials for automotive and aerospace engineering. Weinheim: Willey-VCH, 2006. 
MUSIANI, M. Electrodeposition of composites: an expanding subject in electrochemical material science. Electrochim. Acta, 45:3397-3402. 2000.

PARTHASARADY, N. V. Practical electroplating handbook. Englewood Cliffs, New Jersey: Prentice Hall, 2009.

POSTLETHWAITE, J.; NESIC, S. Erosion-corrosion in single and multiphase flow. In: REVIE, R. W. (ed) Uhligh's corrosion handbook. 2. ed. New York: John Willey, 2000.

SCHWEITZER, P. A. Fundamentals of corrosion. Boca Raton: CRC Press, 2010.

SURVILA, A.; MOCKUS, Z.; KANAPECKAITE, S.; STALNIONIS, G.; JUSKENAS, R.; JASULAITIENE, V. Codeposition of zinc and copper in gluconate-sulfate solutions. J. Electrochem. Soc. 160:D428-D433. 2013.

TUliO, P. C.; RODRIGUES, S. E. B.; CARLOS, I. A. The influence of SiC and $\mathrm{Al}_{2} \mathrm{O}_{3}$ micrometric particles on the electrodeposition of $\mathrm{ZnNi}$ films and the obtainment of $\mathrm{ZnNi}-\mathrm{SiC}$ and $\mathrm{ZnNi}-\mathrm{Al}_{2} \mathrm{O}_{3}$ electrocomposite coatings from slightly acidic solutions. Surf. Coat. Technol. 202:91-99. 2007.

VAGRAMYAN, T.; LEACH, J. S. L.; MOON, J. R. On the problems of electrodepositing brass from non-cyanide electrolytes. Electrochim. Acta 24:231-236. 1979.

VERINCK, E. D. Economics of corrosion. In: REVIE, R. W. (ed) Uhligh's corrosion handbook. 2. ed. New York: John Willey, 2000.

WALSH, F. C.; DE LEON, C. P. A review of the electrodeposition of metal matrix composite coatings by inclusion of particles in a metal layer: an established and diversifying technology. Trans. Inst. Met. Finish. 92:83-98. 2015. 